\title{
Development of cost effective protective clothing for the Ber fruit harvesters
}

\author{
SANDEEP BAINS, DEVINDER KAUR AND MANISHA SETHI
}

Received: 29.03.2017; Revised: 21.09.2017; Accepted: 07.10.2017

See end of the paper for authors' affiliations

\section{SANDEEP BAINS}

Department of Apparel and Textile

Science, Punjab Agricultural

University, LUDHIANA (PUNJAB)

INDIA

Email : sandeepct@pau.edu
ABSTRACT : The major problem encountered by the Ber fruit farm workers is during plucking the fruit, in which they get cuts and wounds on hands/arms and legs due to thorns and splinters. This leads to large lesions and infection. Looking into their problem cost effective protective clothing were developed for the farm workers working in Ber fruit orchards to meet occupational health hazards. The developed Kurta pyjama as protective clothing was stitched from non woven fabric of $70 \mathrm{GSM}$ and underlining of $100 \%$ cotton fabric with $126 \mathrm{GSM}$. To further prevent the thorns from entering the body, Nehru Collar was stitched at neck, with front opening and elastic band at the full length sleeves and ankle of Pyjama.

KEY WORDS: Ber, Protective clothing, Harvesters, Fruit

- HOW TO CITE THIS PAPER : Bains, Sandeep, Kaur, Devinder and Sethi, Manisha (2017). Development of cost effective protective clothing for the Ber fruit harvesters. Asian J. Home Sci., 12 (2) : 360-365, DOI: 10.15740/HAS/AJHS/12.2/360-365. 